NEW TRENDS IN PLANT SYSTEMATICS

\title{
The use of digital image-based morphometrics to study the phenotypic mosaic in taxa with porous genomes
}

\author{
Christian Lexer ${ }^{1,2}$, Jeffrey Joseph ${ }^{1}$, Marcela van Loo ${ }^{1}$, Gerhard Prenner ${ }^{1}$, Berthold Heinze ${ }^{3}$, \\ Mark W. Chase ${ }^{1}$ \& Don Kirkup ${ }^{4}$ \\ ${ }^{1}$ Jodrell Laboratory, Royal Botanic Gardens, Kew, Richmond, Surrey, TW9 3DS, U.K. \\ ${ }^{2}$ Unit of Ecology \& Evolution, Department of Biology, University of Fribourg, 1700 Switzerland. \\ christian.lexer@unifr.ch (author for correspondence) \\ ${ }^{3}$ Institute of Forest Genetics, Federal Research and Training Centre for Forests, Natural Hazards, and \\ Landscape, Hauptstrasse 7, 1140 Vienna, Austria \\ ${ }^{4}$ Identification Systems and Morphometrics Section, Herbarium, Royal Botanic Gardens, Kew, Richmond, \\ Surrey, TW9 3AB, U.K.
}

\begin{abstract}
Rapid recent developments in DNA sequencing and genetic marker technologies call for the establishment of cost-effective, automated phenotyping assays for evolutionary biology and systematics, so that the effects of DNA polymorphisms and epigenetic changes on the phenotype can be evaluated. We discuss the use of digital image-based morphometrics in evolutionary biology and systematics with special emphasis on studies of taxa with porous genomes, i.e., taxa that do not conform to the traditional view of whole-genome isolation between species. We outline the phenomenon of the 'phenotypic mosaic' in taxa with porous genomes using welldocumented examples from the literature and describe three important challenges arising for taxonomists: (1) character conflict in phylogenetic studies, (2) biased sampling of traits in morphological studies, and (3) cryptic ecological speciation. We demonstrate the use of geometric morphometrics using a combined molecular and morphometric dataset from an interspecific hybrid zone between two divergent Eurasian species of Populus, $P$. alba (white poplar) and P. tremula (European aspen). Elliptic Fourier analysis (EFA)-based morphometric data were collected for 527 leaf specimens from 84 trees with known genomic composition as determined by a set of 30 nuclear DNA microsatellites. In addition, to demonstrate the ease of scoring functionally relevant phenotypes via digital image analysis, quantitative differences in leaf reflectance were examined and their structural basis determined using scanning electron microscopy (SEM). The EFA results indicate a heritable inter-individual component for symmetric aspects and an important intra-individual component for asymmetric aspects of variation in leaf outlines. Symmetric traits displayed a striking variety of phenotypes in hybrids compared to their parental species, consistent with the notion of the phenotypic mosaic. Linear discriminant analysis of these morphometric traits revealed (1) clear differentiation between parental species and (2) divergence between recombinant hybrids and their sympatric backcross parent $P$. alba, mediated primarily by two $P$. tremula-like and two transgressive traits. Our results demonstrate the usefulness of geometric morphometrics to interrogate multiple independent phenotypic characters and detect individual traits affected by introgression and divergence in taxa with porous genomes. Digital image-based morphometrics holds great promise for large-scale studies of relationships between DNA polymorphism and phenotypes in evolutionary biology.
\end{abstract}

KEYWORDS: admixture, digital image analysis, ecological speciation, elliptic Fourier analysis, geometric morphometrics, hybrid zone, landmarks, Populus alba, Populus tremula, porous genome

\section{INTRODUCTION}

Recent years have seen great progress in biological systematics. Several signs indicate that molecular approaches to systematics will continue to enjoy rapid development in the years ahead. For instance, DNA 'barcodes' hold the promise to facilitate rapid assessments of species richness in particular geographic regions or taxonomic groups, aid species delimitation, and speed up identification of cryptic species (Hebert \& al., 2004; Chase \& al., 2005; Lahaye \& al., 2008). At the same time, new developments in non-Sanger based DNA sequencing technologies raise hopes that systematists will be able to examine not only genealogies of a handful of neutral marker genes, but also those of genes directly involved in adaptation and speciation (reviews by Wu, 2001; Lexer \& Widmer, 2008). Dynamic developments in molecular methods have led to a steady reduction of costs for 
DNA sequencing and DNA-based genetic marker analysis (Schlötterer, 2004). As a result, systematists are now beginning to experience what the plant and livestock breeding communities have been experiencing for years: that the difficulty or cost of accurately phenotyping individual samples or specimens often resembles or even exceeds that of the accompanying DNA tests, especially where complex traits need to be measured in experimental, homogeneous environments (Neale \& Savolainen, 2004).

In breeding as in systematics, phenotypic traits rather than DNA variants are the ultimate focus of attention. Systematists may use molecular sequence data as a convenient tool for phylogenetic reconstruction, but ultimately interest will be on phenotypes of relevance to ecology and evolutionary biology reflected through patterns of their distributions on phylogenetic trees. Phenotypes of interest may include key innovations (Schluter, 2000), traits directly involved in reproductive isolation such as floral traits associated with pollinator shifts (Schemske \& Bradshaw, 1999; Cozzolino \& Scopece, 2008), traits known to be linked to differential adaptation and thus to ecological speciation (Schwarzbach \& al., 2001; Rosenthal \& al., 2002), and ordinary betweenspecies differences (Orr, 2001), many of which are now known to be maintained by divergent natural selection (Rieseberg \& al., 2002; Lexer \& al., 2003a). Whereas some of these traits will be relatively easy to measure, e.g., instances of discrete colour polymorphisms linked to pollinator shifts, the vast majority of phenotypic differences between populations, species, or higher order taxa will be quantitative (Lynch \& Walsh, 1998; Barton \& al., 2007) and will thus require accurate and objective measurement and analysis. A discussion of recent techniques in morphometrics and their application to evolutionary biology is thus timely.

Here, we discuss the application of morphometrics to a particularly challenging and rewarding topic in systematics and evolutionary biology, the study of taxa with porous genomes, which are taxa that do not conform with the traditional view of 'whole genome isolation' between species. Instead in a 'genic view' of species barriers, there are some regions of the genome that are protected from interspecific gene flow, whereas others are not (Wu, 2001). This genic view of species boundaries applies to many organisms, including birds, fish, insects, and plants. We briefly review selected studies that have addressed the phenotypic mosaic in diploid plant taxa with porous genomes, provide a brief outline of morphometric techniques available for the rapid generation and management of phenotypic datasets and discuss their use in evolutionary biology. As an example, we present and discuss a combined morphometric and molecular dataset for two hybridizing Eurasian Populus species, P. alba (white poplar) and $P$. tremula (European aspen).

\section{Phenotypic mosaics in taxa with porous ge- nomes-a challenge for taxonomists}

A mosaic view of species. - The genic view of speciation $(\mathrm{Wu}, 2001)$ stated that newly emergent species are likely to experience gene flow, which may extend throughout their entire evolutionary history and may affect considerable portions of their genome. However, it will be greatly restricted around loci directly or indirectly involved in reproductive isolation and species differentiation (Wu, 2001; Lexer \& Widmer, 2008). One aspect of this complex interplay between gene flow, recombination and selection is that genomes are not fixed entities, but rather are porous, facilitating movement of some genes across species boundaries while preventing transfer of others. This is predicted by theory and computer simulations (Wu, 2001; Gavrilets \& Vose, 2005; Coyne \& Orr, 2004), and the existence of porous genomes in phenotypically well differentiated taxa has been confirmed by molecular work in plants (e.g., Martinsen \& al., 2001; ScottiSantaigne \& al., 2004; Savolainen \& al., 2006; Lexer \& al., 2007; Yatabe \& al., 2007; Minder \& Widmer, 2008; review by Lexer \& Widmer, 2008). The term 'genomic mosaic' was coined to describe the genomic composition of such populations and taxa and was put forward as an integral part of divergence in the presence of gene flow in sympatry or parapatry (Coyne \& Orr, 2004; Smadja $\&$ al., 2008; Via \& West, 2008). Of course, a 'genomic mosaic' will also result in a phenotypic mosaic whenever genetic loci controlling measurable phenotypic traits are re-shuffled by interspecific recombination in hybrids or introgressants. This general principle is readily illustrated by phenotypic studies that have addressed a specific mode of speciation with gene flow in plants, namely homoploid hybrid speciation, i.e., speciation involving hybridization between taxa of the same ploidy. This is exemplified most easily by the well-documented cases of homoploid hybrid speciation in wild annual sunflowers (Helianthus spp.).

The phenotypic mosaic in homoploid hybrids. - At least eight studies have examined the phenotypes of one or more of the three well-known homoploid Helianthus hybrid species, $H$. anomalus, $H$. deserticola, and H. paradoxus, relative to their two parental species, H. annuus and $H$. petiolaris, under greenhouse (Schwarzbach \& al., 2001; Welch \& Rieseberg, 2002; Rosenthal \& al., 2002; Rieseberg \& al., 2003; Karrenberg \& al., 2006) and field conditions (Lexer \& al., 2003b; Gross \& al., 2004; Ludwig $\&$ al., 2004). In the largest of the greenhouse-based experiments (reported in Rosenthal \& al., 2002; Rieseberg \& al., 2003), 40 quantitative morphological, ecophysiological, and life history traits were measured in population samples of all three hybrid sunflower species and their two parents in a homogeneous environment, and differences in trait means between species were determined. The results 
revealed the full breath of phenotypic patterns expected in recombinant hybrids between two well-diverged species. In H. anomalus, for instance, seven characters were classified as intermediate between the two parental species, ten were more like $H$. petiolaris, five were more like H. annuus, and thirteen were transgressive (extreme) compared to the parental species; the other two hybrid species displayed similarly complex phenotypic mosaics as well (Rieseberg \& al., 2003). Examination of the other two sunflower hybrid species in the same greenhouse experiment revealed a similar variety of phenotypic patterns, $H$. paradoxus being the most divergent with 15 extreme and eight intermediate traits (Rieseberg \& al., 2003).

A particularly valuable aspect of this series of experiments is that the genetic architecture of all traits was elucidated using quantitative trait locus (QTL) mapping (Lexer $\&$ al., 2003a, 2005a; Rieseberg \& al., 2003). Quantitative trait loci are equivalent to chromosome blocks that carry one or more genes controlling quantitative phenotypic traits (Lynch \& Walsh, 1998). This work indicated that much of the mosaic-like patterns seen in hybrids arose due to re-shuffling of genetic material from the two parental species, e.g., most of the transgressive phenotypes in hybrids could be attributed to new combinations of alleles with opposing effects in each parent (Rieseberg \& al., 2003). This indicates an important role for recombination among loci with measurable individual effects that add up to yield the overall phenotype. Of course, dominance (interactions between alleles of the same locus) and epistasis (interactions between alleles of different loci) must be expected to contribute to hybrid phenotypes as well (deVincente \& Tanksley, 1993; Rieseberg \& al., 1999).

Genetic mapping in Helianthus spp. also revealed extensive linkage and/or pleiotropy of QTL along chromosomes, thus indicating extensive genetic correlations among the studied traits (Rieseberg \& al., 2003; Lexer \& al., 2005a). Linkage refers to instances where the genes controlling two or more traits are located in close proximity on a chromosome, whereas the term pleiotropy is reserved for instances where two or more traits are controlled by one and the same gene; both phenomena lead to genetic correlations (Lynch \& Walsh, 1998). Although the observation of extensive genetic correlations in the Helianthus example is of relevance to understanding of the genetics of homoploid hybrid speciation (Rieseberg \& al., 2003), it also serves to demonstrate a more general point of special interest to the present contribution: the systematist's verdict on phenotypes seen in taxa with porous genomes will depend to a large degree on the correlation structure of the traits. Clearly, genetically independent (i.e., unlinked) traits will provide the greatest power for detecting mosaic-like patterns due to interspecific recombination in hybrids or introgressants. We shall discuss further below the potential of morphometric analysis to generate such datasets of independent traits. First, we will outline the three most important challenges for taxonomy posed by the phenotypic mosaic in taxa with porous genomes.

Table 1. Three taxonomic issues arising from the phenotypic mosaic in taxa with porous genomes, including brief description of each issue, references for further reading, and potential role of geometric morphometrics to ameliorate each issue.

\begin{tabular}{|c|c|c|c|}
\hline Taxonomic issue & Description & $\begin{array}{l}\text { Suggested references } \\
\text { for further reading }\end{array}$ & $\begin{array}{l}\text { Potential of geometric morphomet- } \\
\text { rics to ameliorate issue }\end{array}$ \\
\hline $\begin{array}{l}\text { Character conflict in } \\
\text { phylogenetic studies }\end{array}$ & $\begin{array}{l}\text { Hybridization and reticulation in } \\
\text { taxa with porous genomes (e.g., in } \\
\text { taxa that originated through recent } \\
\text { adaptive radiation) lead to discrep- } \\
\text { ancies between phylogenetic trees } \\
\text { derived from different characters. }\end{array}$ & $\begin{array}{l}\text { Schluter, } 2000 \\
\text { Felsenstein, } 2004 \\
\text { Linder \& Rieseberg, } \\
2004 \\
\text { Via \& West, } 2008\end{array}$ & $\begin{array}{l}\text { Use morphometric data to identify } \\
\text { specific traits (and ultimately genes) } \\
\text { affected by divergent selection during } \\
\text { recent bouts of ecological speciation, } \\
\text { to guide choice of characters or genes } \\
\text { used in phylogenetic work. }\end{array}$ \\
\hline $\begin{array}{l}\text { Biased sampling of } \\
\text { traits in morphological } \\
\text { studies }\end{array}$ & $\begin{array}{l}\text { Unintended choice of genetically } \\
\text { correlated traits (= traits that are } \\
\text { transmitted from parents to offspring } \\
\text { together because of linkage or } \\
\text { pleiotropy of the underlying genes) } \\
\text { leads to the failure to detect recom- } \\
\text { binant hybrids. }\end{array}$ & $\begin{array}{l}\text { Falconer \& Mackay, } \\
1996 \\
\text { Lynch \& Walsh, } 1998 \\
\text { Conner, } 2004\end{array}$ & $\begin{array}{l}\text { Use orthogonal variables (e.g., } \\
\text { principal components) derived from } \\
\text { morphometric data to maximize the } \\
\text { number of statistically and genetically } \\
\text { independent traits in phenetic studies. }\end{array}$ \\
\hline $\begin{array}{l}\text { Cryptic cases of eco- } \\
\text { logical speciation }\end{array}$ & $\begin{array}{l}\text { High overall phenotypic similarity } \\
\text { between backcrossed hybrids (= in- } \\
\text { trogressants) and their backcross } \\
\text { parental species, coupled with limi- } \\
\text { tations in the number of phenotypic } \\
\text { traits measured, leads to the failure } \\
\text { to detect individual traits affected by } \\
\text { introgression and divergence. }\end{array}$ & $\begin{array}{l}\text { Seehausen \& al., } 2004 \\
\text { Mallet, } 2007 \\
\text { Jiggins \& al., } 2008\end{array}$ & $\begin{array}{l}\text { Use morphometric data to isolate those } \\
\text { specific traits most affected by intro- } \\
\text { gression and divergence as expected } \\
\text { under models of ecological speciation } \\
\text { in the presence of gene flow. }\end{array}$ \\
\hline
\end{tabular}




\section{Character conflict in phylogenetic studies. -} The phenotypic mosaic is not only an integral aspect of homoploid hybrid speciation as seen in Helianthus. It also is an important but often overlooked general aspect of speciation in taxa with porous genomes and can pose serious challenges for taxonomists (Table 1). The perhaps most widely known challenge is the character conflict often observed in cladistic studies (Felsenstein, 2004; Linder $\&$ Rieseberg, 2004). The genic view of speciation implies that the various loci in the genome will have different genealogical histories, so it is intuitive that different DNA sequences, or phenotypic characters coded by these loci, will have discordant phylogenetic distributions. This can be pictured as an extension of the type of phenotypic mosaic seen in homoploid Helianthus hybrids (above) to the more general case of recombinant hybrids or introgressed accessions frequently encountered in taxa with porous genomes (keeping in mind that homoploid hybrid or 'recombinational' speciation as seen in Helianthus represents a highly specific outcome of hybridization; Buerkle \& al., 2000). Character conflict in taxa with porous genomes is expected to be particularly pronounced between traits or DNA sequences that evolve neutrally on one hand and those directly or indirectly affected by divergent selection on the other (Via \& West, 2008). Of course, other factors such as lineage sorting - the stochastic sorting in recently diverged species of alleles derived from a polymorphic ancestor-may contribute to phylogenetic incongruence as well (Felsenstein, 2004; Linder \& Rieseberg, 2004). In general, character conflict will facilitate the detection of reticulate evolution, but it will result in great uncertainty about the precise phylogenetic relationships among the taxa studied. In the case of recent adaptive radiations, an unorthodox, provocative possibility to ameliorate character conflict may be to focus phylogenetic analysis on exactly those characters or genes known to be affected by divergent selection during recent bouts of ecological speciation (Via \& West, 2008). We note that adaptive introgression of the selected traits and alleles may greatly complicate phylogenetic inference in such cases, depending on the strength of reproductive isolation and the tempo of its evolution.

Biased sampling of traits in morphological studies. - If phenotypes in taxa with porous genomes are studied in a phenetic context (statistical clustering of individuals based on their overall morphological similarity), then a similar issue arises, as different classifications may be reached depending on the characters chosen and their correlations. Hybrids or introgressants in such cases may be classified as either one or the other parental species if the traits used happen to be parental-like, or as entirely new species if the traits are divergent, i.e., intermediate or transgressive. Genetic correlations (linkage and/ or pleiotropy) between examined traits will amplify the error of morphological classification even further, i.e., loci controlling different aspects of floral or vegetative morphology may be pleiotropic or closely linked so that classification based on different sets of closely correlated traits will yield contrasting results. Digital image-based morphometric analysis yielding multiple independent or orthogonal traits can ameliorate this problem and reveal the mosaic nature of recombinant hybrids, as outlined by our dataset on European Populus below.

Cryptic cases of ecological speciation. - Another potential challenge for taxonomists in the context of taxa with porous genomes is that recombinant backcrosses between divergent species will often be "pulled back into the orbit of one parental species" (Rieseberg $\&$ al., 2006). For instance, in the Rieseberg \& al. (2006) review on 'The nature of plant species', contemporary hybridization among species of the same ploidy failed to cause significant and consistent taxonomic problems in a large linear model-based analysis involving many families. This indicates that divergence triggered by homoploid hybridization may often remain cryptic, but this is because taxonomists often focus on "key characters" that they intuitively believe to have discriminating power and ignore those that are "unreliable". These "unreliable" characters may include those that could provide evidence of recombination if analysed in a less biased context. Nevertheless, there appear to be exemptions to this general pattern in many taxonomic groups. For instance, correspondence between classical 'taxonomic species' and phenotypic clusters from phenetic analysis in the Rieseberg \& al. (2006) review was still $<50 \%$ for species groups with contemporary homoploid hybridization in several plant families, e.g., Asteraceae (Cherniawsky \& Bayer, 1997), Campanulaceae (Lammers, 1996), Ericaceae (Haber, 1983), Liliaceae (Ness \& al., 1990), Melastomataceae (Figueiredo, 2001), Plumbaginaceae (Feliner \& al., 2001) and Solanaceae (Sullivan, 1985; Giannattasio \& Spooner, 1994; review by Rieseberg \& al., 2006), so it appears that the phenotypic effects of contemporary homoploid hybridization are not always blurred by backcrossing.

The failure of contemporary homoploid hybridization to disrupt congruence consistently between phenetic clusters and traditional 'taxonomic species' (Rieseberg \& al., 2006) suggests the possibility that cases of ecological speciation in the face of gene flow, e.g., homoploid hybrid speciation, may often be overlooked by morphological studies. This may happen easily in cases of 'hybrid trait speciation', a recently suggested mode of ecological speciation that is different from the classical 'recombinational' model of homoploid hybrid speciation applicable to Helianthus (Buerkle \& al., 2000). 'Hybrid trait speciation' refers to speciation that involves hybridization and subsequent introgression of traits that allow recombinant backcross hybrids to colonize a novel adaptive peak (Mallet, 2007; Jiggins \& al., 2008). The outcome of hybridization 
in these cases will be speciation rather than mere adaptive introgression whenever the introgressed trait also has the potential to influence reproductive isolation directly, as has been suggested for wing colour patterns in Heliconius butterflies (Jiggins \& al., 2008; we note that the conditions under which this is likely to occur may be relatively rare, as discussed by Duenez-Guzman \& al., in press). In the case of morphological traits in plants (e.g., flower morphology), analysis methods that capture multiple independent morphometric variables simultaneously should maximize the chance to detect backcrosses and identify individual traits affected by such interspecific introgression and subsequent divergence.

\section{The promise of geometric morphometrics- the evolutionary biologist's view}

Morphometrics in the age of digital image analysis. - Classical morphometrics in plants involved manual measurements of quantitative traits from floral or vegetative tissues and computation of informative variables as simple functions (usually as distance metrics) of the raw data, but these overlooked important biomathematical aspects of the original measurements (Bookstein, 1996). More recently, a suite of methodologies coined 'geometric morphometrics' was developed to describe the shape of organismal features quantitatively (Rohlf \& Archie, 1984; Zelditch \& al., 2004). Morphometrics is currently experiencing a renaissance, fuelled in part by the rise of digital photography and development of affordable image scanning equipment, both of which facilitate rapid extraction of geometric features using digital image analysis. Outline or 'landmark' points of features of organisms can readily be digitized using publicly available computer software (http://rsbweb.nih.gov/ij/; http://life.bio.sunysb.edu/ee/ rohlf/software.html; Bylesjö \& al., 2008), and subsequent decomposition of digitized data can be achieved using curve fitting methods such as elliptic Fourier analysis (EFA) in the case of organismal object outlines (Rohlf \& Archie, 1984; White \& al., 1988) or superimposition methods such as thin plate splines (TPS) and relative warps in the case of configurations of organismal landmarks (Jensen \& al., 2002; Adams \& al., 2004).

Briefly, EFA fits a Fourier function to closed outlines of objects (Kuhl \& Giardina, 1982), and parameters of the function are the so-called Fourier coefficients that represent these curves. These Fourier coefficients are sometimes evaluated directly, or more usually, they are subjected to multivariate methods to reduce dimensionality (hence redundancy in the data) and extract those aspects of the data (e.g., those principal components) that capture most variation in outline shape for use as shape variables in subsequent analyses (see White \& al., 1988 or Yoshioka \& al., 2004 for application of EFA to plants).
The superimposition family of methods, on the other hand (e.g., TPS and relative warps), places several so-called landmarks on the digitized shape, thus pinpointing putative biologically homologous locations on the object (see Shipunov \& Bateman, 2005 for a recent application to plants). TPS reveals the amount of force or 'bending energy' required to transform a rectangular grid superimposed on one specific shape into another shape (Rohlf \& Slice, 1990). Again, this is often followed by multivariate statistical analysis to bring out the most important aspects of morphometric data. For more detailed descriptions of the mathematics underlying EFA and landmark methods see, e.g., Rohlf \& Archie (1984), Adams \& al. (2004) and Yoshioka \& al. (2004). Below, we shall outline the potential of these methodologies with special emphasis on evolutionary biology.

Morphometrics for evolutionary biologists. - As outlined earlier, recent advances in molecular genetics and genomics greatly facilitate the ongoing quest to understand the genetics and evolution of adaptations and formation of new species, which are central goals of evolutionary biology (Barton \& al., 2007). The ball is now back in the court of morphometrics to provide the analytical methods and phenotypic data against which important changes at the DNA sequence level can be evaluated. We already know that differences in morphology frequently indicate important developmental evolutionary changes in plant organs (Piazza \& al., 2005; Shipunov \& Bateman, 2005), and morphological traits are often pleiotropic or closely linked with other traits of known adaptive significance (e.g., Lexer \& al., 2005a; review by Lexer \& Widmer, 2008).

The promise of digital image-based morphometrics for evolutionary biology lies in its ability to generate and manage quickly large amounts of phenotypic data representing many aspects of phenotype (Jensen \& al., 2002; Adams \& al., 2004; Zelditch \& al., 2004). Also, the multivariate techniques frequently used to explore elliptic Fourier- or landmark-based data, such as principal component analysis (PCA), yield synthetic variables that represent orthogonal vectors and therefore minimize the degree of intercorrelation among studied traits (e.g., Yoshioka \& al., 2004). This potentially allows evolutionary biologists to identify and 'isolate' individual traits affected by adaptive changes between divergent populations or species.

In the case of taxa with porous genomes, the use of multiple, genetically uncorrelated and, therefore, independent morphometric features should facilitate identification of exactly those traits that contribute to character conflict because they are direct or indirect targets of natural selection (Lande \& Arnold, 1983). It will also enable identification of recombinant hybrids or introgressants in morphological studies. Because each advanced-generation hybrid may receive a different set of alleles in the "game of dice" occurring during recombination in each generation, 
there are a great number of potential combinations of traits (Lexer \& al., 2003b; Gross \& al., 2004; Ludwig \& al., 2004). Geometric morphometrics can help identify recombinant hybrids because it yields independent phenotypic variables - traits unlikely to be affected by pleiotropy or linkage. We note that the heritability of EFA-principal components and their high degree of genetic independence (= absence of linkage or pleiotropy among QTL) have been demonstrated in several plant taxa recently (e.g., Iwata \& al., 2002; Uga \& al., 2003). A potential application of modern morphometric methods also lies in the identification of introgressed traits such as those thought to be involved in 'hybrid trait speciation' (Mallet, 2007; Jiggins \& al., 2008) and similar models of ecological speciation (Seehausen \& al., 2004). The detection of introgressed traits in advanced backcrosses requires methods to visualize a large number of phenotypic traits, a requirement that should be met by modern morphometric approaches.

\section{Case study Populus}

The porous genome in Populus. - The diploid genus Populus (chromosome number: $2 n=38$; genome size: 550 megabases in the case of $P$. trichocarpa; Tuskan \& al., 2006) includes several textbook examples for phenotypically well-differentiated taxa with porous genomes (Eckenwalder, 1996). The two North American cottonwood species $P$. fremontii and $P$. angustifolia, for instance, form extensive hybrid zones in the western United States (Whitham, 1989). The geographic extent of nuclear genomic introgression across these zones of overlap and hybridization varies greatly among marker loci (Martinsen \& al., 2001), which indicates that the species barrier is porous. The great diversity of genotypes found in these natural hybrid populations was utilized to develop and test fundamental concepts in 'community genetics' to understand how heritable variation in dominant or 'foundation species' may affect associated communities and ecosystem processes (Whitham \& al., 2006).

In Eurasia, P. alba (white poplar) and P. tremula (European aspen) represent increasingly well-understood examples of Populus species with porous genomes. These two taxa are highly divergent with respect to their ecology. Populus alba is a floodplain species able to tolerate extended periods of being waterlogged, whereas $P$. tremula is an upland pioneer that does not normally tolerate flooding (Lexer \& al., 2004; Fischer \& al., 2005). The two species also differ in numerous other ecological traits, such as phenology and leaf morphology (Fischer \& al., 2005); note that QTL for leaf morphological characters in Populus are often closely linked or pleiotropic with QTL for biomass accumulation and growth (e.g., Wu \& al., 1997; Rae \& al., 2006, 2007). Populus alba and P. tremula hybridize in multiple localities, resulting in a variety of recombinant genotypes that coexist within extensive 'mosaic' hybrid zones (hybrids are often referred to as $P$. $\times$ canescens) situated primarily in lowland floodplain forests (Bartha, 1991; Fossati \& al., 2004; Lexer \& al., 2005b). Introgression across hybrid zones of these species varies greatly when unlinked nuclear genetic marker loci are sampled from the genome (Lexer \& al., 2007). All these attributes render this hybridizing species pair a promising study system for understanding the genetics of reproductive isolation and ecological trait differences in taxa with porous genomes (Lexer \& Widmer, 2008; Buerkle \& Lexer, 2008).

Porosity of species barriers in Populus may be important not only in terms of present-day ecological differentiation and biotic interactions but also in terms of macroevolutionary patterns (Eckenwalder \& al., 1996). Frequent introgression of alleles and traits across porous species boundaries (Rajora \& Dancik, 1992; Martinsen \& al., 2001; Floate, 2004; Fossati \& al., 2004; Lexer \& al., 2005 b) enhances the phenotypic repertoire of the recipient species, which may contribute to changes of species ranges and possibly to population divergence and speciation. In the case of the Eurasian P. nigra (black poplar), for instance, a role for hybridization in speciation and species evolution has been suggested based on character conflict between nuclear and organellar DNA (Smith \& Sytsma, 1990; Hamzeh \& Dayanandan, 2004; Cervera \& al., 2005). To our knowledge, however, the extent to which homoplasy or incomplete lineage sorting may have contributed to these patterns in $P$. nigra is currently not clear.

Here, we used a combined morphometric and molecular dataset of the Eurasian species P. alba and P. tremula to demonstrate the use of digital image-based morphometrics for studying the phenotypic mosaic in taxa with porous genomes. We sampled and digitized leaf material of trees from a Central European hybrid zone and sorted them into parental-like and hybrid genotypes using a molecular hybrid index based on nuclear microsatellite DNA markers known for their ability to differentiate the two species (Lexer \& al., 2007). Then we compared multiple phenotypic traits derived from digital image-based morphometrics among the parental-like and hybrid genotypes and assessed overall phenotypic differentiation of parents and hybrids. We discuss these data in the context of general issues raised above.

\section{MATERIALS AND METHODS}

Morphometric data were collected for 527 fully expanded leaves from 84 trees of the Austrian Danube Valley hybrid zone and neighbouring parental populations described previously by Lexer \& al. (2005b); molecular data were collected for the same sample of 84 individuals. The sampled zone of overlap between P. alba and 
P. tremula covered ca. $90 \mathrm{~km}$ of the Danube Valley with a sampling midpoint near Vienna $\left(48.26^{\circ} \mathrm{N}, 16.27^{\circ} \mathrm{E}\right)$. The 527 leaves corresponded to an average of 5 leaves $( \pm 1$ std. dev.) measured for each tree. Specimens of mature leaves were collected from short-shoots only, as long-shoots are known to be heteroblastic (Fischer \& al., 2005). All samples were pressed and dried using standard herbarium techniques, and additional leaf material for DNA extraction was collected in silica gel (Chase \& Hills, 1990).

Assignment of specimens to three genotypic classes, P. alba, P. tremula, and P. ×canescens hybrids, was achieved prior to the morphometric analysis by a molecular hybrid index (Buerkle, 2005) based on 30 co-dominant nuclear microsatellites. This exclusively molecular marker-based taxon assignment was chosen to avoid circular reasoning during subsequent morphometric analysis. Also, nuclear microsatellites are known to differentiate these two species well (allele frequency differentials up to 0.99 ; Lexer \& al., 2007). The microsatellite markers included the 20 loci previously used by Lexer $\&$ al. (2005b), plus the following ten loci developed by Tuskan \& al. (2004), Van der Schoot \& al. (2000), and Smulders \& al. (2001): ORPM 369, ORPM 26, ORPM 190, ORPM 23, WPMS 17, ORPM 203, ORPM 268, ORPM 374, ORPM 16 and ORPM 430. Primer information for all loci is available at http://www.ornl.gov/sci/ipgc/ssr_resource.htm. The 30 microsatellites were assayed in the laboratory as described by Lexer $\&$ al. (2005b). Subsequently, the maximum-likelihood based hybrid index developed by Buerkle (2005) was calculated based on parental allele frequencies of the same two local reference population samples of $P$. alba and $P$. tremula previously used by Lexer $\&$ al. $(2005 \mathrm{~b}$; 2007) and Van Loo \& al. (2008). The molecular hybrid index (HI), which corresponds to the proportion of the genome inherited from $P$. alba, was used to sort specimens into the three genotypic classes (P. tremula: $\mathrm{HI} \leq 0.05 ; P$. $\times$ canescens hybrids: $0.05<\mathrm{HI}<0.95$; $P$. alba: $\mathrm{HI} \geq 0.95$ ). Using these sorting criteria, molecular analysis indicated that the sampled specimens comprised 21 individuals of P. alba, 24 of $P$. tremula, and 39 of $P$. $\times$ canescens. The increased representation for $P$. $\times$ canescens was expected based on earlier studies of this hybrid zone (Lexer \& al., 2005b, 2007) and considered appropriate for this study because of the greater genetic and morphological variability expected for the hybrid population compared to parental species (Lexer \& al., 2005b, 2007).

All specimens were digitized using an HP scanjet $7400 \mathrm{c}$ flatbed scanner using fixed settings (resolution 300 dpi, medium sharpness, true colour). The $5 \pm 1$ (std. dev.) specimens available for each individual had both their upper and lower (adaxial and abaxial) surfaces scanned. The upper leaf surface images were processed to produce binary bitmap files. Then, landmark points for the base and apex of the leaf as well as $\mathrm{x}$ and y pixel coordinates of each leaf outline, the traces all starting at the leaf base, were recorded for subsequent EFA with the computer program tpsDIG (http://life.bio.sunysb.edu/ee/ rohlf/software.html). In addition, images of lower leaf surfaces were scanned and saved in the form of Tiff images for measurement of leaf reflectance (described further below). A calibration strip was used to obtain standard threshold exposure values by manually setting the black and white points prior to scanning each leaf.

The digitised leaf outlines were first aligned with respect to the leaf apex and base landmarks using Bookstein's coordinate transformation prior to EFA with normalisation for size, all operations carried out using NTSYSpc (Exeter Software, New York, U.S.A.). Preliminary analysis (by PCA) revealed that the Fourier coefficients of the first eight harmonics could be divided into two uncorrelated groups of PCs: one containing those coefficients that described symmetric variation around the midline of the leaf (labeled A and D coefficients) and the other containing those that described asymmetric variation in the leaf outlines (B and C coefficients). Fourier coefficients from each group were then subjected to separate principal component analyses based on their respective covariance matrices, and all subsequent analyses of leaf outlines were carried out on these two sets of principal components (EFA-PCs).

Both symmetric and asymmetric EFA-PCs were first characterized for the entire dataset by analysis of variance (ANOVA) with 'individuals' and 'genotypic class' (P. alba, P. $\times$ canescens hybrids, $P$. tremula) as predictor variables. These analyses indicated which of the EFA-PCs differed significantly between individuals in each genotypic class and, thus, whether an EFA-PC had a heritable component (see Yoshioka \& al., 2004). A more elaborate way of estimating heritabilities in natural populations is by comparing a matrix of phenotypic similarities between pairs of individuals with estimates of pair-wise relatedness inferred by molecular markers, but this approach requires much larger sample sizes to reach adequate power (Ritland, 2000).

The top 16 symmetric EFA-PCs were examined further using an aggregated dataset of averages for each PC for each sampled tree. The phenotype distributions for each PC in each genotypic class (P. alba, P. $\times$ canescens hybrids, $P$. tremula) were inspected using simple box plots, and pairwise differences between $P$. $\times$ canescens and either parent were tested for each EFA-PC using pairwise non-parametric Mann-Whitney U tests. A linear discriminant analysis (LDA) of the top 16 symmetric PCs was carried out to examine the overall phenotypic differentiation between the three genotypic classes and to assess the contribution of each EFA-PC to the total differentiation. All of these statistical procedures were carried out with NTSYS and SPSS (SPSS Inc., Chicago, Illinois, U.S.A.). 
To illustrate further the range of possibilities of digital image-based morphometrics, a simple but highly informative additional trait was measured from the scanned leaf specimens: reflectance of leaf undersides. Reflectance in terms of the mean greyscale value of a standard area of the leaf undersides was measured from scanned images of each leaf using the Image $J$ software (http://rsbweb.nih.gov/ij/features.html). The rationale for these measurements was that reflectance should provide a simple surrogate for hairiness of leaf undersides, a diagnostic trait that differentiates P. alba and P. tremula when measured in mature leaves of short-shoots (Fischer $\&$ al., 2005). The micromorphological basis of differences in leaf reflectance was established using scanning electron microscopy (SEM) of samples from each species. For SEM, fractions of air-dried leaves were mounted onto specimen stubs using nail polish, coated with platinum in an Emitech K550 sputter coater (Emitech, Ashford, U.K.) and examined using a Hitachi S-2500 SEM (Hitachi High Technologies Corp., Tokyo, Japan). Images were saved as TIFF files, and final labeling was done using Adobe Photoshop CS. These measurements were included in graphical and statistical analyses along with the EFA-PCs from the leaf outline analysis as described above.

\section{RESULTS}

Inter-individual component of variation in morphometric traits. - The first 16 principal components extracted from the symmetric and asymmetric elliptic Fourier coefficients ( $=$ the first 16 symmetric and asymmetric EFA-PCs, respectively) were considered for comparisons of phenotypes across individuals and genotypic classes. Multifactor ANOVAs using 'genotypic class' (inferred from the molecular hybrid index) and 'individual' (based on the $5 \pm 1$ replicates available for each tree) as predictor variables indicated that all symmetric EFA-PCs had significant between-individual effects ( $F$-statistics from ANOVA; $P<0.001$; not shown), except for EFA-PCs 9 and 13 for which $F$-tests were only marginally significant $(P<0.1)$. By contrast, except for one principal component (PC 3) none of the asymmetric EFA-PCs had a significant inter-individual effect, thus indicating an important non-heritable component to asymmetric aspects of variation in leaf morphology. To keep interpretation of results simple, only symmetric EFA-PCs were examined further in the present study.

Patterns of phenotypic differentiation for individual traits. - Seven of the top 16 symmetric EFA-PCs were selected for the purpose of illustrating the phenotypic mosaic in these Populus taxa. The seven EFA-PCs were chosen based on the diversity of their phenotypic patterns (Fig. 1) and the importance of their contribution to the overall phenotype as revealed by a linear discriminant analysis (LDA; Table 2, discussed further below). Figure 1 shows reconstructed leaf outlines (using eight Fourier harmonics) illustrating the effects of each of the seven symmetric EFA-PCs on the mean leaf shape (means \pm 5 standard deviations to exaggerate the shape differences). Figure 2 shows reconstructions of the first seven asymmetric EFA-PCs for comparison.

Means and standard errors of symmetric phenotypic variables in each genotypic class, $P$. alba, $P$. $\times$ canescens, and P. tremula, are shown in Fig. 3, along with results of non-parametric pair-wise Mann-Whitney $U$ tests for differences in means. Principal components 1 and 2 were identified as $P$. alba-like based
PC 1

PC 2

PC 3

\section{PC 4}
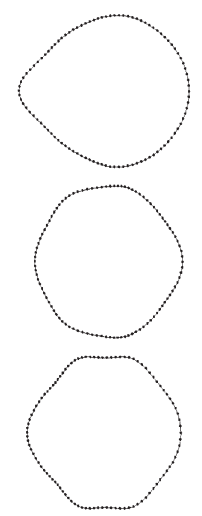

PC 6
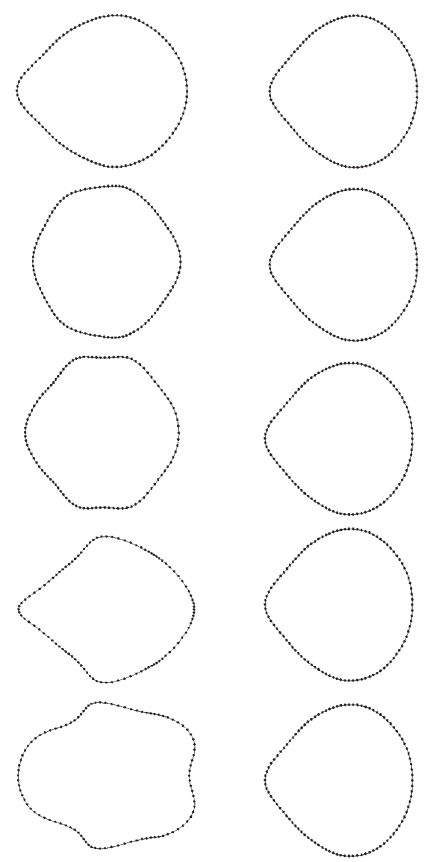

PC 9
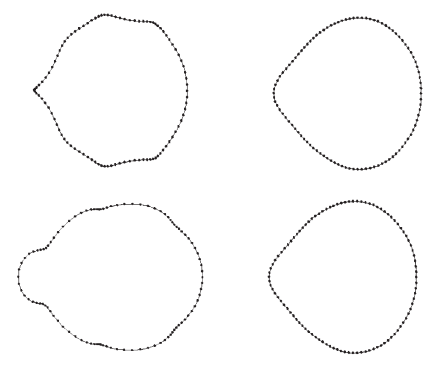

$<$ mean

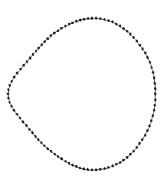

mean
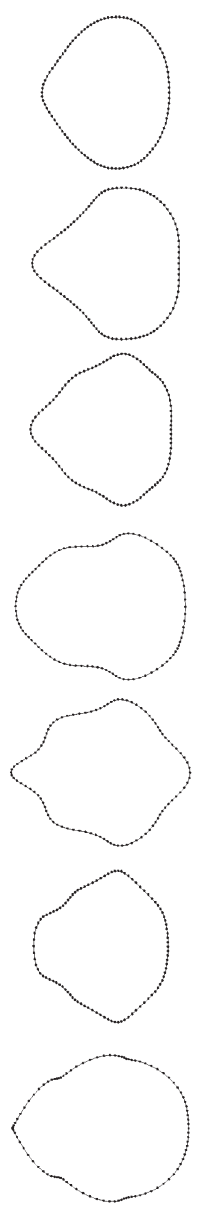

$>$ mean
Fig. 1. The effects of seven EFA-PCs describing symmetric aspects of variation in leaf outlines in a Central European hybrid zone between two divergent European Populus species, $P$. alba and $P$. tremula. Shown are the projected means $\pm \mathbf{5}$ standard deviations for each PC. The seven PCs were chosen for illustration based on their loadings on the first two axes of a linear discriminant analysis (LDA; Table 2) and on the diversity of their phenotypic patterns. See text for details. 
on the non-parametric tests, 3 and 6 were identified as $P$. tremula-like, 9 as intermediate, and 4 and 15 as transgressive. In the case of the transgressive PCs, the $P$. $\times$ canescens sample included multiple individuals with extreme trait values relative to their parents, resulting in a (non-significant) increase in trait means (Fig. 3).

Micromorphological basis and phenotypic patterns for leaf reflectance. - SEM demonstrated that reflectance measured important diagnostic features of the lower leaf surfaces in these species. In P. tremula, stomata are sunken into the folded leaf surface that is covered with a distinct layer of crystalline wax (Fig. 4A). By contrast, in P. alba the surface of the leaf is not visible because it is covered by a dense indumentum of hairs (i.e., a tomentose leaf surface; Fig. 4B). These differences in surface properties are captured by the digital leaf reflectance measurements, resulting in significant differences in reflectance between P. alba and P. tremula (Fig. 3), whereas P. $\times$ canescens tends to be intermediate for this trait (Fig. 3).

Table 2. Linear discriminant analysis (LDA) of the first 16 principal components (PCs) describing symmetric aspects of variation in leaf outlines in 527 leaves from 84 trees of a Central European hybrid zone between the two phenotypically divergent European Populus species, $P$. alba and P. tremula.

\begin{tabular}{crr}
\hline $\begin{array}{c}\text { Principal } \\
\text { component }\end{array}$ & LD1 $^{\mathbf{b}}$ & LD2 $^{\mathbf{b}}$ \\
\hline PC 1 & $\mathbf{1 . 2 6 8}$ & 0.177 \\
PC 2 & $\mathbf{- 1 . 1 8 2}$ & -0.055 \\
PC 3 & $\mathbf{0 . 6 1 4}$ & $-\mathbf{0 . 7 4 3}$ \\
PC 4 & -0.457 & $\mathbf{- 0 . 4 8 9}$ \\
PC 5 & -0.173 & -0.037 \\
PC 6 & 0.478 & $\mathbf{- 0 . 4 6 3}$ \\
PC 7 & -0.043 & 0.063 \\
PC 8 & -0.240 & 0.002 \\
PC 9 & $-\mathbf{0 . 7 6 5}$ & 0.269 \\
PC 10 & 0.281 & -0.366 \\
PC 11 & -0.440 & -0.121 \\
PC 12 & 0.318 & 0.320 \\
PC 13 & 0.256 & -0.052 \\
PC 14 & 0.069 & -0.278 \\
PC 15 & -0.404 & $-\mathbf{0 . 4 1 0}$ \\
PC 16 & -0.227 & 0.156
\end{tabular}

${ }^{a}$ The PCs are derived from the symmetric elliptic Fourier coefficients of the first eight harmonics of an elliptic Fourier analysis (EFA) of the leaf outlines of the sampled leaf specimens.

${ }^{\mathrm{b}}$ Linear discriminant (LD) axes 1 and 2 explain $89 \%$ and $11 \%$ of the variation in the phenotypic data, respectively. The four PCs with the highest loadings on each discriminant axis are indicated by bold type. See text for details.
PC 1
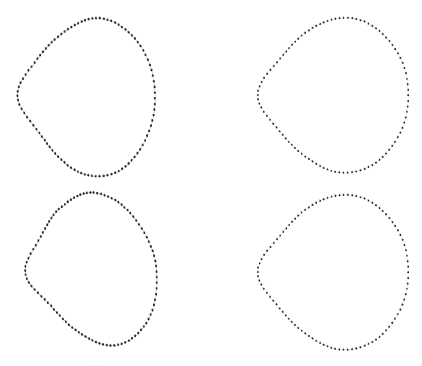

PC 3

PC 2

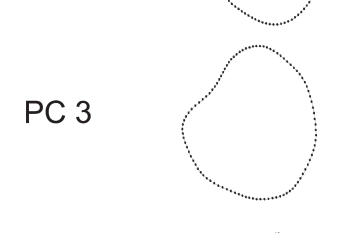

PC 4
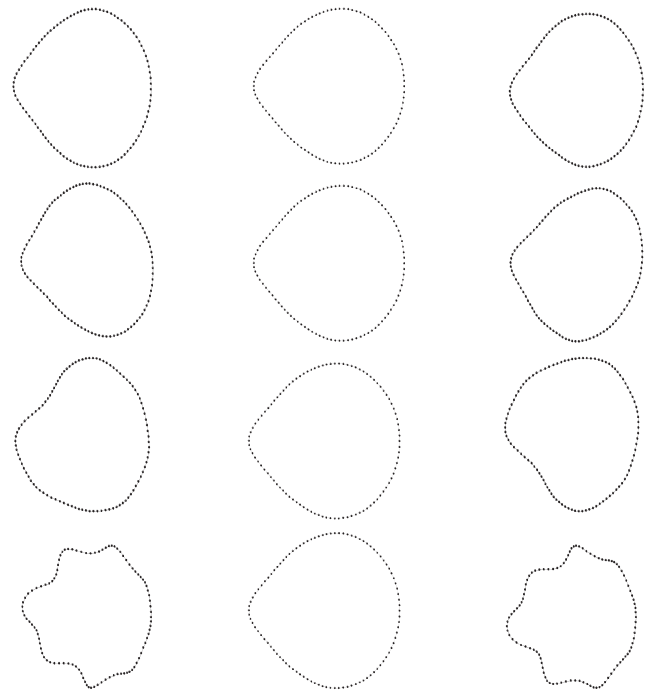

PC 4
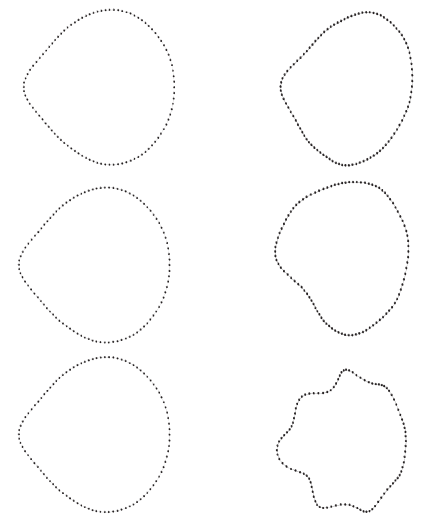

PC 5
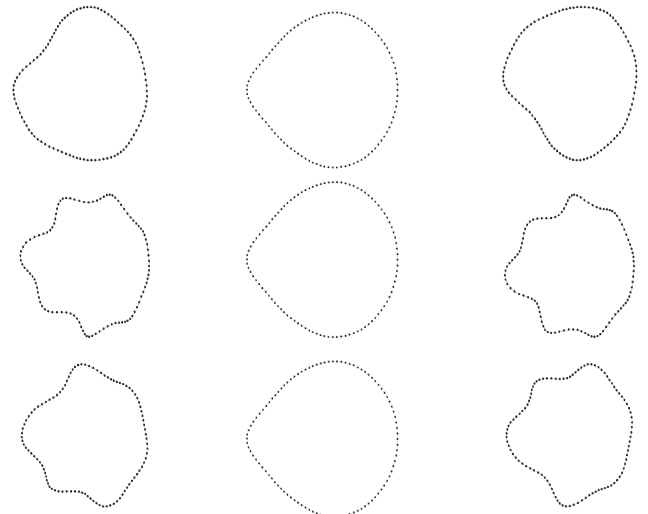

PC 6
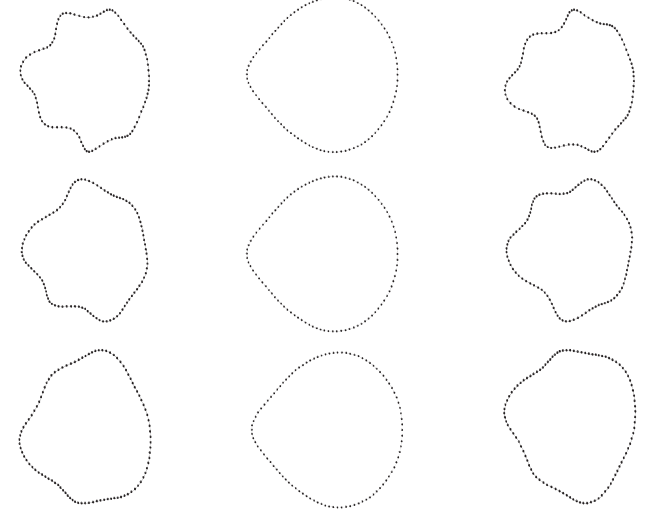

PC 7
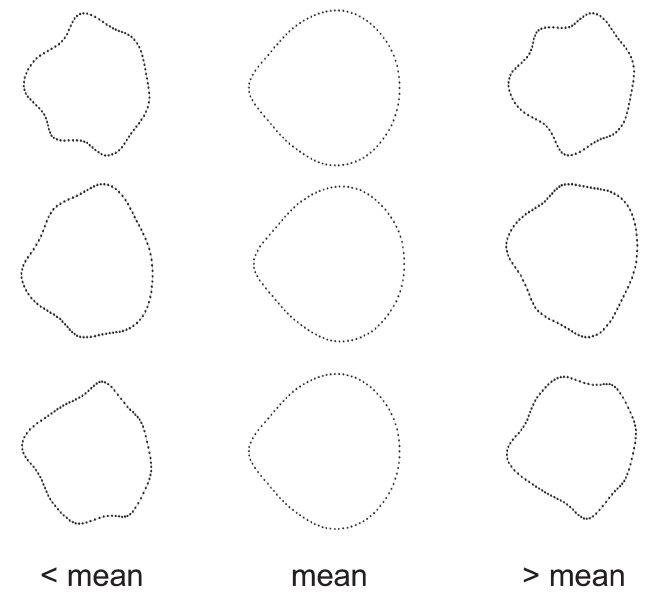

$>$ mean

Fig. 2. The effects of the first seven EFA-PCs describing asymmetric aspects of variation in leaf outlines (projected means $\pm \mathbf{5}$ standard deviations), for comparison to the symmetric principal components seen in Fig. 1. For details see text and legend of Fig. 1.

Linear discriminant analysis of leaf shape components. - Loadings of each EFA-PC on the two linear discriminant axes are shown in Table 2. EFA-PCs $1,2,3$ and 9 contributed most to the variation between the two parental species seen on the first discriminant axis (Table 2; Fig. 5). These describe differences in leaf shape (length/width), simple aspects of lobation and sharpness of the leaf tip (Fig. 1). In addition, EFA-PCs $3,4,6$ and 15 contributed most to the variation between $P$. $\times$ canescens and its backcross parent, P. alba, seen on the second discriminant axis (Table 2; Fig. 5). These principal components describe more complex and composite aspects of lobation and leaf architecture (Fig. 1). Hybrids were P. tremula-like for two of these traits (EFA-PC 3 and 6) and transgressive for the other two (EFA-PCs 4 and 15; Fig. 3). 

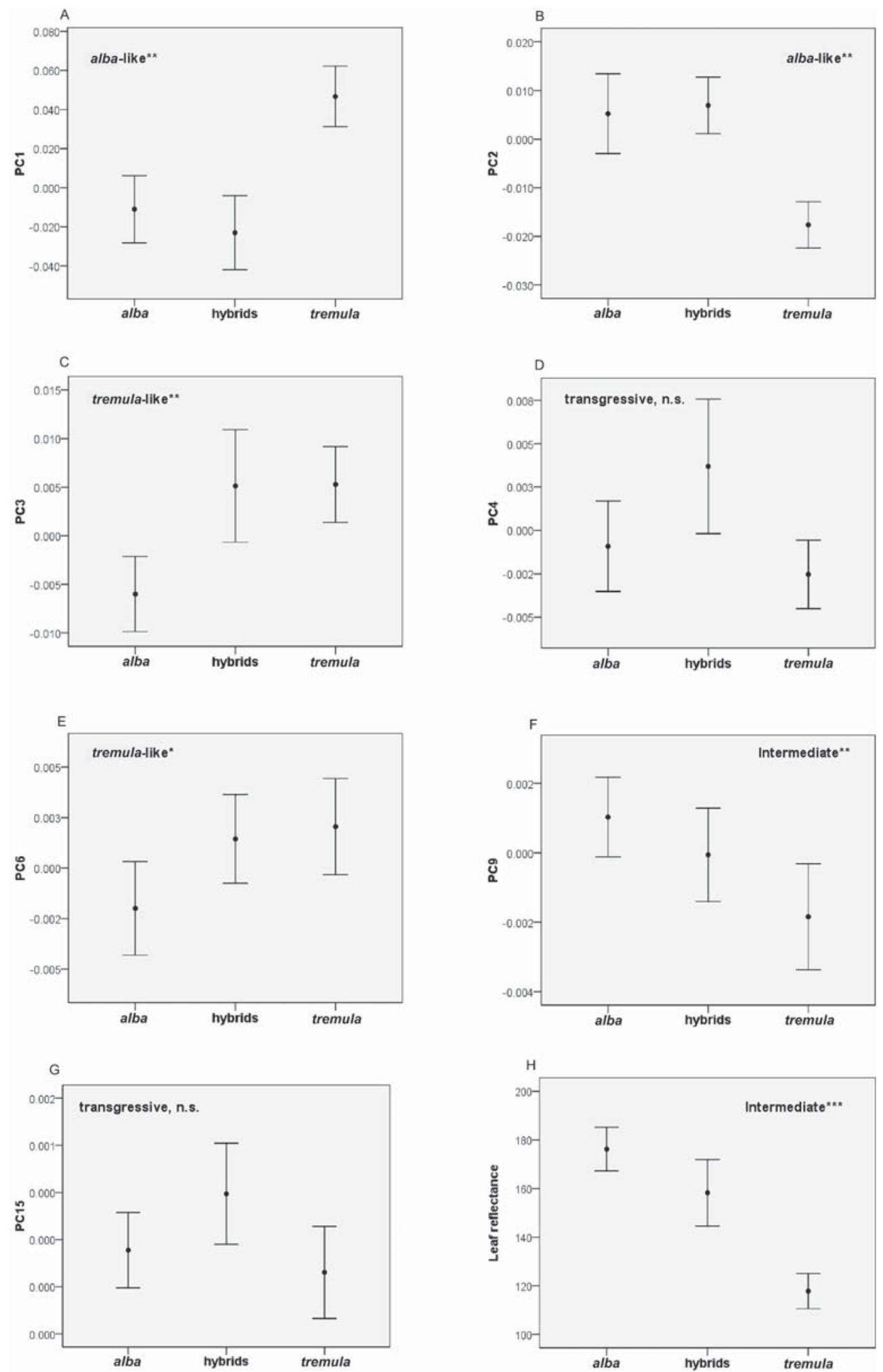

Fig. 3. Means and standard errors for leaf reflectance and seven EFA principal components (PCs) describing symmetric aspects of variation in outlines in each of three genotypic classes identified in a Central European Populus hybrid zone: $P$. alba, $P$. xcanescens, $P$. tremula. The three genotypic classes were identified based on a molecular hybrid index as described in the text. Hybrid phenotypes relative to their parental species were then classified based on non-parametric Mann-Whitney U tests $\left({ }^{*} P<0.05\right.$; $\left.{ }^{* *} P<0.01,{ }^{* * *} P<0.005\right)$. Several $P$. xcanescens individuals had extreme phenotypes for the two transgressive traits (PCs 4 and 15), resulting in a non-significant (n.s.) increase in means for these traits. 

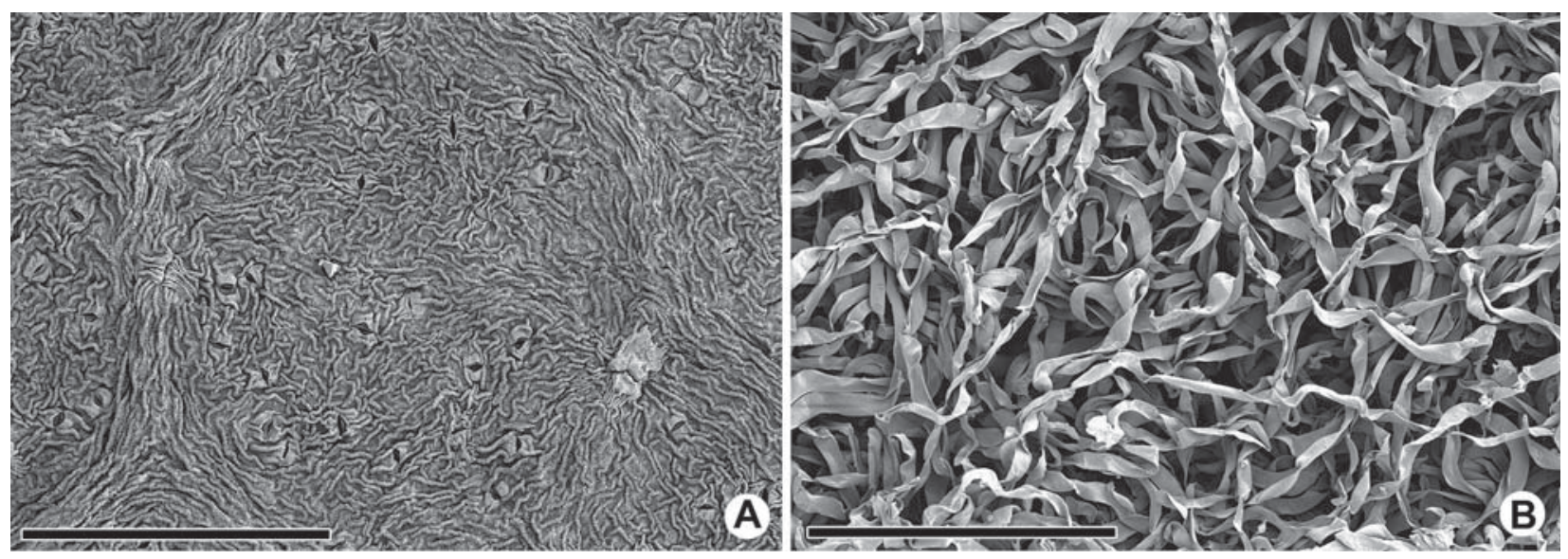

Fig. 4. Scanning electron microscopy (SEM) micrograph of abaxial leaf surfaces. A, Populus tremula, stomata are sunken into the folded leaf surface which is covered with a distinct layer of crystalline wax. B, Populus alba, the surface of the leaf is not visible because it is covered by a dense indumentum of hairs (i.e., a tomentose leaf surface). Bars $=200 \mu \mathrm{m}$.

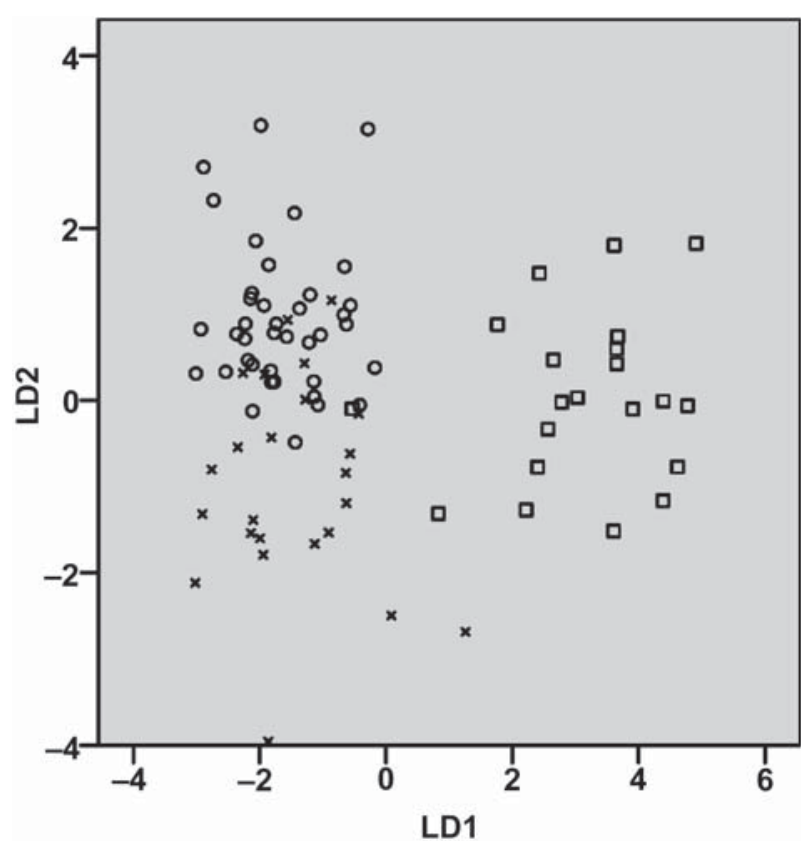

Fig. 5. Linear discriminant analysis (LDA) of the first 16 EFA principal components describing symmetric aspects of variation in outlines in a Central European hybrid zone between the two Eurasian Populus species, $P$. alba and $P$. tremula. Linear discriminant (LD) axes 1 and 2 explained $89 \%$ and $11 \%$ of the variation in the data, respectively. Circles: $P$. alba; squares: $P$. tremula; crosses: $P$. xcanescens.

\section{DISCUSSION}

Exploring heritable components of morphometric traits. - One finding of our study was that all symmetrical EFA-PCs had a significant inter-individual component whereas asymmetric coefficients in general had none. The significant inter-individual effects of symmetric EFA-PCs suggest a heritable component for these traits (Yoshioka \& al., 2004). A possible explanation for absence of significant inter-individual effects in asymmetric traits, on the other hand, is developmental instability. Such developmental perturbations with effects on the phenotype can arise due to the breakdown of coadapted gene complexes in hybrids and introgressants (Dobzhansky, 1970).

In principle, significant inter-individual effects of symmetric traits could also be due to plasticity associated with ecological differences between the sites of origin of the sampled trees. It would have been preferable to grow each specimen in a common garden, but this was not possible because rooting success of clonal cuttings in wild populations of these species is low $(<5 \%$ : Heinze and coworkers, unpub. data). Nevertheless, an initial ANOVA-based comparison of the EFA-PCs of individuals sampled west and east of Vienna, i.e., along the main climatic gradient present in the sampling area, did not yield any significant difference at the $5 \%$ level (not shown). This suggests that the significant inter-individual effects seen for symmetric traits were due to genetic rather than environmental differences. We note that QTL mapping studies in Populus indicate a strong heritable component for leaf morphological traits (e.g., Wu \& al., 1997; Rae \& al., 2006).

The phenotypic mosaic in European Populus. - Clearly, symmetric shape components (EFA-PCs) examined capture different aspects of length, width, shape and lobation (Fig. 1). Short-shoots of P. alba have characteristic three- to five-lobed leaves, whereas those of $P$. tremula have round, ovate leaves without clearly developed lobes (Fischer \& al., 2005). Leaf reflectance 
(hairiness) was highly informative for discriminating species and hybrids as well (Fig. 3: bottom right), demonstrating yet another approach to convert a diagnostic morphological feature into a measurable quantitative trait with known structural basis (Fig. 4).

The diversity of phenotypes seen in Figs. 1 and 3 also makes intuitively clear why hybrids between $P$. alba and P. tremula have long been so confusing for taxonomists and ecologists (Senghas \& Seybold, 1993; Lazowsky, 1997; Fischer \& al., 2005), resulting even in the description of $P$. $\times$ canescens as a distinct species (Muhle-Larsen, 1970). Diagnostic traits commonly used by botanists to differentiate these taxa include the shape and lobation of leaves (Senghas \& Seybold, 1993; Fischer \& al., 2005). Dissection of these traits into multiple orthogonal phenotypic vectors using EFA-PCs (Figs. 1, 3) revealed the mosaic-like nature of these phenotypes, most likely due to the involvement of several genes, which is testable through QTL mapping in experimental crosses (Bradshaw \& Stettler, 1995; Wu \& al., 1997; Rae \& al., 2006; 2007) or admixture mapping of phenotypic differences directly in natural hybrid zones (Buerkle \& Lexer, 2008). Apparently, traditional botanists have been misled by the fact that each individual found in sympatric or parapatric populations of $P$. alba and P. tremula may carry variable combinations of alleles controlling exactly those traits used for their classification (e.g., leaf shape, lobation, colour of leaf undersides, petiole length and shape of petiole cross-section, catkin morphology and stem colour). If such suites of traits are dissected into multiple independent variables using morphometric techniques as shown here in the case of leaf outlines, the mosaiclike nature of recombinant hybrids becomes apparent.

Reassembling the mosaic. - If we explore the overall phenotype that results from combining all 16 symmetric EFA-PCs using LDA, then two clear trends emerge. Firstly, P. alba and P. tremula are differentiated for their overall phenotype already on the first linear discriminant axis (LD1), which explains $89 \%$ of the variation in the data (Fig. 5: circles and squares, respectively). Secondly, individuals of $P$. $\times$ canescens tend to diverge from their sympatric backcross parent $P$. alba on the second discriminant axis (LD2), which explains $11 \%$ of the variation (Fig. 5: crossshaped symbols). Positioning of most $P . \times$ canescens accessions closer to $P$. alba in morphospace makes sense; molecular marker-based studies indicate that most hybrids from this population are backcrossed to $P$. alba, and in this study the microsatellite-based hybrid index of the sampled $P$. $\times$ canescens hybrids was $0.80 \pm 0.25 \mathrm{std}$. dev. (for comparison, the molecular hybrid index was $1.00 \pm 0.00$ for P. alba and $0.00 \pm$ 0.01 for $P$. tremula).
The LDA revealed a striking pattern of phenotypic differentiation between $P . \times$ canescens and the sympatric backcross parent $P$. alba along LD2 (Fig. 5), hybrids being $P$. tremula-like and transgressive for those traits that contributed most to the variation seen along this axis ( $P$. tremula-like traits: EFA-PCs 3 and 6, transgressive traits: EFA-PCs 4 and 15; Table 2; Fig. $3)$. The P. tremula-like traits may indicate genetic loci for which $P$. tremula alleles introgress more readily than expected compared to genome-wide expectations and/or loci for which the P. alba allele is recessive, which are testable hypotheses (Lexer \& al., 2007). Both scenarios would explain why most accessions of $P$. $\times{ }_{C a}$ nescens are divergent from their backcross parent in their overall phenotype (Fig. 5). The transgressive trait (EFA-PC 4) offers an additional explanation for divergent phenotypes in hybrids; transgressive characters are often under natural selection in habitats occupied by hybrids, which can contribute to divergence processes in homoploid hybrid lineages (Lexer \& al., 2003b; Rieseberg \& al., 2003; Gross \& al., 2004; Ludwig \& al., 2004).

Divergence with gene flow forms an important part of several models of ecological speciation (Rieseberg \& al., 2003; Seehausen, 2004; Mallet, 2007; Jiggins \& al., 2008). Although we have currently no reason to believe that $P$. ${ }^{\times}$canescens is on the road to evolving strong and enduring reproductive isolation, the observation of measurable phenotypic divergence (Fig. 5) matches our recent finding of increased finescale spatial genetic structure in hybrid phenotypes sampled from the same natural hybrid zone, even after adjusting for differences in the propensity of hybrids and parents to reproduce asexually (Van Loo \& al., 2008). These spatial genetic patterns led Van Loo \& al. (2008) to suggest the presence of assortative mating in hybrids, which would also help explain the origin of the phenotypic patterns observed here. Regardless of the most likely evolutionary trajectory of hybrids, our dataset demonstrates the use of geometric morphometrics to identify individual traits that contribute to overall phenotypic divergence in taxa with porous genomes.

\section{CONCLUSION AND FUTURE PERSPECTIVES}

Improved methods of digital image analysis and geometric morphometrics greatly facilitate collection and management of phenotypic data in evolutionary biology. These approaches hold great potential to speed up and thus reduce the costs of phenotyping assays necessary to understand the phenotypic effects of DNA sequence 
polymorphisms and epigenetic changes at the population level and to track evolution of phenotypes at macro-evolutionary timescales (Givnish \& Sytsma, 1997; Schluter, 2000; Paun \& al., 2007; Stinchcombe \& Hoekstra, 2008). Also, the management of morphometric databases is straight-forward because all information is digital.

Geometric morphometrics is particularly suitable for the study of taxa with porous genomes, as demonstrated by our case study on European Populus. Studies of taxa with porous species boundaries are of great current interest in plant evolutionary biology because they promise to yield novel insights into speciation and species evolution in the face of gene flow, including mechanisms underlying ecological speciation (Coyne \& Orr, 2004; Gross \& al., 2004; Gavrilets \& Vose, 2005; Mallet, 2007; Jiggins \& al., 2008; Lexer \& Widmer, 2008). As discussed for the Populus example, the power of modern morphometric methods lies in their ability to reveal the mosaic-like nature of recombinant hybrids through the analysis of multiple independent (i.e., genetically uncorrelated) traits and detect individual traits that contribute to overall phenotypic divergence and are affected by interspecific introgression.

One of the biggest challenges for taxonomists and other evolutionary biologists is to understand the genetic and functional basis of phenotypic differences that facilitate or accompany population divergence and speciation. A suite of concepts and methodologies has been developed for mapping genotype onto phenotype and identifying the genetic basis of adaptation and speciation using genetic mapping in experimental crosses (Schemske \& Bradshaw, 1999) and natural populations (reviews by Neale \& Savolainen, 2004; Buerkle \& Lexer, 2008). All these approaches would benefit greatly from automated and rapid phenotyping assays, such as those discussed here. In particular, the large number of phenotypic variables generated by digital image-based geometric morphometrics could contribute to our understanding of the nature and strength of genetic correlations between morphological traits on one hand and underlying developmental and physiological characters on the other. In Populus, for example, analyses of a rapidly growing QTL database suggests there are extensive genetic correlations among morphological, developmental and ecological traits in the form of linkage and/or pleiotropy (Bradshaw \& al., 1995; Wu \& al., 1997; Frewen \& al., 2000; Rae \& al., 2006, 2007).

A promising approach to elucidate the genetic basis of morphological species differences in taxa with porous genomes is to map phenotype onto genotype in natural hybrid zones, i.e., in localities where otherwise well isolated and differentiated taxa meet and mate. This approach, also known as 'admixture mapping', makes use of the segregation and recombination of chromosome segments derived from two divergent parental gene pools in interspecific hybrid zones (Briscoe \& al., 1994). Recent developments in admixture mapping indicate a great potential of this approach to identify and map genetic loci that control quantitative phenotypic species differences (Buerkle \& Lexer, 2008; Gompert \& Buerkle, 2009). Mapping morphometric traits to the genome using admixture mapping would provide a means of testing several of the hypotheses outlined earlier in this paper, e.g., regarding the genetic mechanisms involved in trait introgression and divergence. It can also help the taxonomist identify hybrid accessions so that characters of the "pure" species can be more accurately characterised, which can help to clarify species boundaries. However, these are just some of the many potential applications of geometric morphometrics. We predict that rapid phenotyping methods will increasingly be in high demand for many other applications, whenever the interest is in understanding relationships between DNA sequence polymorphism and phenotypes of relevance to taxonomy and evolutionary biology.

\section{ACKNOWLEDGEMENTS}

We thank Hans Herz and Wilfried Nebenführ of BFW Vienna, Austria, Christian Fraissl and Franz Kovacs of the Danube Floodplain National Park, the Forstverwaltung Lobau of the Vienna City Council, Herbert Tiefenbacher and several other private landowners for support during field work in Austria, Simon Mayo of the Royal Botanic Gardens, Kew, for lively discussions about morphometry and species boundaries, and Alex Widmer and Toby Pennington for helpful comments on the manuscript. This work was supported by new investigator award NE/C507037/1 and standard grant NE/E016731/1 of the British Natural Environment Research Council (NERC) to CL.

\section{LITERATURE CITED}

Adams, D.C., Rohlf, F.J. \& Slice, D.E. 2004. Geometric morphometrics: ten years of progress following the 'revolution'. Ital. J. Zool. 71: 5-16.

Bartha, D. 1991. Bastardisierung und Introgression bei den Weisspappelpopulationen (Populus alba L.) in Ungarn. Mitt. Deutsch. Dendrol. Ges. 80: 177-180.

Barton, N.H., Briggs, D.E.G., Eisen, J.A., Goldstein, D.B. \& Patel, N.H. 2007. Evolution. Cold Spring Harbor Laboratory Press, Cold Spring Harbor.

Bookstein, F.L. 1996. Biometrics, biomathematics and the morphometric synthesis. Bull. Math. Biol. 58 313-365.

Bradshaw, H.D. \& Stettler, R.F. 1995. Molecular genetics of growth and development in Populus. IV. Mapping QTLs 
with large effects on growth, form, and phenology traits in a forest tree. Genetics 139: 963-973.

Briscoe, D., Stephens, J. \& O'Brien, S. 1994. Linkage disequilibrium in admixed populations: applications in gene mapping. J. Heredity 85: 59-63.

Buerkle, C.A. 2005. Maximum-likelihood estimation of a hybrid index based on molecular markers. Molec. Ecol. Notes 5: 684-687.

Buerkle, C.A. \& Lexer, C. 2008. Admixture as the basis for genetic mapping. Trends Ecol. Evol. 23: 686-694.

Buerkle, C.A., Morris, R.J., Asmussen, M.A. \& Rieseberg, L.H. 2000. The likelihood of homoploid hybrid speciation. Heredity 84: 441-451.

Bylesjö, M., Segura, V., Soolanayakanahally, R.Y., Rae, A.M., Trygg, J., Gustafsson, P., Jansson, S. \& Street, N.R. 2008. LAMINA: a tool for rapid quantification of leaf size and shape parameters. BMC Pl. Biol. 8: 82.

Cervera, M.T., Storme, V., Soto, A., Ivens, B., Van Montagu, M., Rajora, O.P. \& Boerjan, W. 2005. Intraspecific and interspecific genetic and phylogenetic relationships in the genus Populus based on AFLP markers. Theor. Appl. Genet. 111: 1440-1456.

Chase, M.W., Hills, H.G. 1991. Silica gel: an ideal material for field preservation of leaf samples for DNA studies. Taxon 40: 215-220.

Chase, M.W., Salamin, N., Wilkinson, M., Dunwell, J.M., Kesanakurthi, R.P., Haidar, N. \& Savolainen, V. 2005. Land plants and DNA barcodes: short-term and long-term goals. Philos. Trans., Ser. B 360: 1889-1895.

Cherniawsky, D.M. \& Bayer, R.J. 1997. Systematics of North American Petasites (Asteraceae: Senecioneae). I. Morphometric analyses. Canad. J. Bot. 76: 23-36.

Conner, J.K. 2004. Genetic mechanisms of floral trait correlations in a natural population. Nature 420: 407-410.

Coyne, J.A. \& Orr, H.A. 2004. Speciation. Sinauer, Sunderland.

Cozzolino, S. \& Scopece, G. 2008. Specificity in pollination and consequences for postmating reproductive isolation in deceptive Mediterranean orchids. Philos. Trans., Ser. B 363: 3037-3046.

DeVincente, M.C. \& Tanksley, S.D. 1993. QTL analysis of transgressive segregation in an interspecific tomato cross. Genetics 134: 585-596.

Dobzhansky, T. 1970. Genetics of the Evolutionary Process. Columbia University Press, New York.

Duenez-Guzman, E.A., Mavàrez, J., Vose, M.D. \& Gavrilets, S. In press. Case studies and mathematical models of ecological speciation. 4. Hybrid speciation in butterflies in a jungle. Evolution.

Eckenwalder, J.E. 1996. Systematics and evolution of Populus. Pp. 7-32 in: Stettler, R.F., Bradshaw, H.D., Heilman, P.E., Hinckley, T.M. (ed.), Biology of Populus, and Its Implications for Management and Conservation. NRC Research Press, Ottawa.

Falconer, T.S. \& Mackay, T.F.C. 1996. Introduction to Quantitative Genetics, 4th ed. Longmans Green, Harlow.

Feliner, G.N. 1992. Multivariate and cladistic analyses of the purple-flowered species of Erysimum (Cruciferae) from the Iberian Peninsula. Pl. Syst. Evol. 180: 15-28.

Felsenstein, J. 2004. Inferring Phylogenies. Sinauer. Sunderland.

Figueiredo, E. 2001. A revision of Calvoa Hook. f. (Melastomataceae). Bot. J. Linn. Soc. 136: 179-205.
Fischer, M.A., Adler, W. \& Oswald, K. 2005. Exkursionsflora für Österreich, Liechtenstein und Südtirol. Land Oberösterreich, Landesmuseum, Linz.

Floate, K.D. 2004. Extent and patterns of hybridization among the three species of Populus that constitute the riparian forest of southern Alberta, Canada. Canad. J. Bot. 82: $253-264$.

Fossati, T., Patrignani, G., Zapelli, I., Sabatti, M., Sala, F. \& Castiglione, S. 2004. Development of molecular markers to assess the level of introgression of $P$. tremula into $P$. alba natural populations. Pl. Breed. (New York) 123: $382-$ 385.

Frewen, B.E., Chen, T.H.H., Howe, G.T., Davis, J., Rohde, A., Boerjan, W. \& Bradshaw, H.D. 2000. Quantitative trait loci and candidate gene mapping of bud set and bud flush in Populus. Genetics 154: 837-845.

Gavrilets, S. \& Vose, A. 2005. Dynamic patterns of adaptive radiation. Proc. Natl. Acad. Sci. U.S.A. 102: 18040-18045.

Giannattasio, R.B. \& Spooner, D.M. 1994. A reexamination of species boundaries between Solanum megistacrolobum and S. toralapanum (Solanum sect. Petota, series Megistacroloba) - morphological data. Syst. Bot. 19: 89-105.

Givnish, T.J. \& Sytsma, K.J. (eds.). 1997. Molecular Evolution and Adaptive Radiation. Cambridge University Press, Cambridge, U.K.

Gompert, Z. \& Buerkle, C.A. 2009. A powerful regressionbased method for admixture mapping of isolation across the genome of hybrids. Molec. Ecol. 18: 1207-1224.

Gross, B.L., Kane, N.C., Lexer, C., Ludwig, F., Rosenthal, D.M., Donovan, L.A. \& Rieseberg, L.H. 2004. Reconstructing the origin of Helianthus deserticola: survival and selection on the desert floor. Amer. Naturalist 164: $145-156$.

Haber, E. 1983. Morphological variability and flavonol chemistry of the Pyrola-Asarifolia complex (Ericaceae) in North America. Syst. Bot. 8: 277-298.

Hamzeh, M. \& Dayanandan, S. 2004. Phylogeny of Populus (Salicaceae) based on nucleotide sequences of chloroplast trnT-trnF region and nuclear rDNA. Amer. J. Bot. 91: 1398-1408.

Hebert, P.D.N., Stoeckle, M.Y., Zemlak, T.S. \& Francis, C.M. 2004. Identification of birds through DNA barcodes. PLOS Biol. 2: 1657-1663.

Iwata, H., Nesumi, H., Ninomiya, S., Takano, Y. \& Ukai, Y. 2002. Diallele analysis of leaf shape variations of citrus varieties based on elliptic Fourier descriptors. Breed. Sci. 52: 89-94.

Jensen, R.J., Ciofani, K.M. \& Miramontes, L.C. 2002. Lines, outlines, and landmarks: morphometric analyses of leaves of Acer rubrum, Acer saccharinum (Aceraceae) and their hybrid. Taxon 51: 475-492.

Jiggins, C.D., Salazar, C., Linares, M. \& Mavarez, J. 2008. Hybrid trait speciation and Heliconius butterflies. Philos. Trans., Ser. B 363: 3047-3054.

Karrenberg, S., Edelist, C., Lexer, C. \& Rieseberg, L. 2006. Response to salinity in the homoploid hybrid species Helianthus paradoxus and its progenitors $H$. annuus and H. petiolaris. New Phytol. 170: 615-629.

Kuhl, F.P. \& Giardina, C.R. 1982. Elliptic Fourier features of a closed contour. Comput. Graphics Image Process. 18: $236-258$.

Lahaye, R., Van der Bank, M., Bogarin, D., Warner, J., 
Pupulin, F., Gigot, G., Maurin, O., Duthoit, S., Barraclough, T.G. \& Savolainen, V. 2008. DNA barcoding the floras of biodiversity hotspots. Proc. Natl. Acad. Sci. U.S.A. 105: 2923-2928.

Lammers, T.G. 1996. Phylogeny, biogeography, and systematics of the Wahlenbergia fernandeziana complex (Campanulaceae: Campanuloideae). Syst. Bot. 21: 397-415.

Lande, R. \& Arnold, S.J. 1983. The measurement of selection on correlated characters. Evolution 37: 1210-1226.

Lazowski, W. 1997. Auen in Österreich - Vegetation, Landschaft und Naturschutz. Monographien, Band 81. Federal Environment Agency, Vienna.

Lexer, C., Buerkle, A., Joseph, J.A., Heinze, B. \& Fay, M.F. 2007. Admixture in European Populus hybrid zones makes feasible the mapping of loci that contribute to reproductive isolation and trait differences. Heredity 98: 74-84.

Lexer, C., Fay, M.F., Joseph, J.A., Nica, M.-S. \& Heinze, B. 2005b. Barriers to gene flow between two ecologically divergent Populus species, P. alba (white poplar) and $P$. tremula (European aspen): the role of ecology and life history in gene introgression. Molec. Ecol. 14: 1045-1057.

Lexer, C., Heinze, B., Alia, R. \& Rieseberg, L.H. 2004. Hybrid zones as a tool for identifying adaptive genetic variation in outbreeding forest trees: lessons from wild annual sunflowers (Helianthus spp.). Forest Ecol. Managem. 197: 49-64.

Lexer, C., Randell, R.A. \& Rieseberg, L.H. 2003a. Experimental hybridization as a tool for studying selection in the wild. Ecology 84: 1688-1699.

Lexer, C., Rosenthal, D.M., Raymond, O., Donovan, L.A. \& Rieseberg, L.H. 2005a. Genetics of species differences in the wild annual sunflowers, Helianthus annuus and H. petiolaris. Genetics 169: 2225-2239.

Lexer, C., Welch, M.E., Raymond, O. \& Rieseberg, L.H. 2003b. The origin of ecological divergence in Helianthus paradoxus (Asteraceae): selection on transgressive characters in a novel hybrid habitat. Evolution 57: 1989-2000.

Lexer, C. \& Widmer, A. 2008. The genic view of plant speciation: recent progress and emerging questions. Philos. Trans., Ser. B 363: 3023-3036.

Linder, C.R. \& Rieseberg, L.H.R. 2004. Reconstructing patterns of reticulate evolution in plants. Amer. J. Bot. 91: 1700-1708.

Ludwig, F., Rosenthal, D.M., Johnston, J.A., Kane, N., Gross, B.L., Lexer, C., Dudley, S.A., Rieseberg, L.H. \& Donovan, L.A. 2004. Selection on leaf ecophysiological traits in a desert hybrid Helianthus species and earlygeneration hybrids. Evolution 58: 2682-2692.

Lynch, M. \& Walsh, B. 1998. Genetics and Analysis of Quantitative Traits. Sinauer, Sunderland.

Mallet, J. 2007. Hybrid speciation. Nature 446: 279-283.

Martinsen, G.D., Whitham, T.G., Turek, R.J. \& Keim, P. 2001. Hybrid populations selectively filter gene introgression between species. Evolution 55: 1325-1335.

Minder, A.M. \& Widmer, A. 2008. A population genomic analysis of species boundaries: neutral processes, adaptive divergence and introgression between two hybridizing plant species. Molec. Ecol. 17: 1552-1563.

Muhle Larsen, C. 1970. Recent advances in poplar breeding. Int. Rev. Forest Res. 3: 1-67.

Neale, D.B. \& Savolainen, O. 2004. Association genetics of complex traits in conifers. Trends Genet. 9: 325-330.
Ness, B.D., Soltis, D.E. \& Soltis, P.S. 1990. An examination of polyploidy and putative introgression in Calochortus subsection Nudi (Liliaceae). Amer. J. Bot. 77: 1519-1531.

Orr, H.A. 2001. The genetics of species differences. Trends Ecol. Evol. 16: 343-350.

Paun, O., Fay, M.F., Soltis, D.E. \& Chase, M.W. 2007. Genetic and epigenetic alterations after hybridization and genome doubling. Taxon 56: 649-656.

Piazza, P., Jasinski, S. \& Tsiantis, M. 2005. Evolution of leaf developmental mechanisms. New Phytol. 167: 693-710.

Rae, A.M., Ferris, R., Tallis, M.J. \& Taylor, G. 2006. Elucidating genomic regions determining enhanced leaf growth and delayed senescence in elevated $\mathrm{CO}_{2}$. Pl. Cell Environ. 29: 1730-1741.

Rae, A.M., Tricker, P.J., Bunn, S.M. \& Taylor, G. 2007. Adaptation of tree growth to elevated $\mathrm{CO}_{2}$ : QTL for biomass in Populus. New Phytol. 175: 59-69.

Rajora, O.P. \& Dancik, B.P. 1992. Genetic characterization and relationships of Populus alba, P. tremula, and $P . \times C a-$ nescens, and their clones. Theor. Appl. Genet. 84: 291298.

Rieseberg, L.H., Archer, M.A. \& Wayne, R.K. 1999. Transgressive segregation, adaptation and speciation. Heredity 83: 363-372.

Rieseberg, L.H., Raymond, O., Rosenthal, D.M., Lai, Z., Livingstone, K., Nakazato, T., Durphy, J.L., Schwarzbach, A.E., Donovan, L.A. \& Lexer, C. 2003. Major ecological transitions in wild sunflowers facilitated by hybridization. Science 301: 1211-1216.

Rieseberg, L.H., Widmer, A., Arntz, A.M. \& Burke, J.M. 2002. Directional selection is the primary cause of phenotypic diversification. Proc. Natl. Acad. Sci. U.S.A. 99: 12242-12245.

Rieseberg, L.H., Wood, T.E. \& Baack, E.J. 2006. The nature of plant species. Nature 440: 524-527.

Ritland K. 2000. Marker-inferred relatedness as a tool for detesting heritability in nature. Molec. Ecol. 9: 1195-1204.

Rohlf, F.J. \& Archie, J.W. 1984. A comparison of Fourier methods for the description of wing shape in mosquitoes (Ritera culicidae). Syst. Zool. 33: 322-317.

Rohlf, F.J. \& Slice, D. 1990. Extension of the procrustes method for the optimal superimposition of landmarks. Syst. Zool. 39: 40-59.

Rosenthal, D.M., Schwarzbach, A.E., Donovan, L.A., Raymond, O. \& Rieseberg, L.H. 2002. Phenotypic differentiation between three ancient hybrid taxa and their parental species. Int. J. Pl. Sci. 163: 387-398.

Savolainen, V., Anstett, M.C., Lexer, C., Hutton, I., Clarkson, J.J., Norup, M.V., Powell, M.P., Springate, D., Salamin, N. \& Baker, W.J. 2006. Sympatric speciation in palms on an oceanic island. Nature 441: 210-213.

Schemske, D.W. \& Bradshaw, H.D. 1999. Pollinator preference and the evolution of floral traits in monkeyflowers (Mimulus). Proc. Natl. Acad. Sci. U.S.A. 96: 11910-11915.

Schlötterer, C. 2004. The evolution of molecular markers-just a matter of fashion? Nature Rev. Genet. 5: 63-69.

Schluter, D. 2000. The Ecology of Adaptive Radiation. Oxford University Press, Oxford, U.K.

Schwarzbach, A.E., Donovan, L.A. \& Rieseberg, L.H. 2001. Transgressive character expression in a hybrid sunflower species. Amer. J. Bot. 88: 270-277.

Scotti-Saintagne, C., Mariette, S., Porth, I., Goicoechea, 
P.G., Barreneche, T., Bodenes, K., Burg, K. \& Kremer, A. 2004. Genome scanning for interspecific differentiation between two closely related oak species [Quercus robur L. and Q. petraea (Matt.) Liebl.]. Genetics 168: 1615-1626.

Seehausen, O. 2004. Hybridization and adaptive radiation. Trends Ecol. Evol. 19: 198-207.

Senghas, K. \& Seybold, S. 1993. Flora von Deutschland und angrenzender Länder. Quelle \& Meyer, Heidelberg.

Shipunov, A.B. \& Bateman, R.M. 2005. Geometric morphometrics as a tool for understanding Dactylorhiza (Orchidaceae) diversity in European Russia. Biol. J. Linn. Soc. 85: $1-12$.

Smadja, C., Galindo, J. \& Butlin, R. 2008. Hitching a lift on the road to speciation. Molec. Ecol. 17: 4177-4180.

Smith, R.L. \& Sytsma, K.J. 1990. Evolution of Populus nigra (sect. Aigeros) - introgressive hybridization and the chloroplast contribution of Populus alba (sect. Populus). Amer. J. Bot. 77: 1176-1187.

Smulders, M.J.M., Van der Schoot, J., Arens, P. \& Vosman, B. 2001. Trinucleotide repeat microsatellite markers for black poplar (Populus nigra L.). Molec. Ecol. Notes 1: 188-190.

Stinchcombe, J. \& Hoekstra, H. 2008. Combining population genomics and quantitative genetics: finding the genes underlying ecologically important traits. Heredity 100 : $158-170$.

Sullivan, J.R. 1985. Systematics of the Physalis viscosa complex (Solanaceae). Syst. Bot. 10: 426-444.

Tanksley, S.D. 1993. Mapping polygenes. Annual Rev. Genet. 27: 205-233.

Tuskan, G.A., DiFazio, S., Jansson, S., Bohlmann, J., Grigoriev, I., Hellsten, U., Putnam, N., Ralph, S., Rombauts, S., Salamov, A., Schein, J., Sterck, L., Aerts, A., Bhalerao RR, Bhalerao RP, Blaudez, D., Boerjan, W., Brun, A., Brunner, A., Busov, V., Campbell, M., Carlson, J., Chalot, M., Chapman, J., Chen, G.L., Cooper, D., Coutinho PM, Couturier, J., Covert, S., Cronk, Q., Cunningham, R., Davis, J., Degroeve, S., Déjardin, A., Depamphilis, C., Detter, J., Dirks, B., Dubchak, I., Duplessis, S., Ehlting, J., Ellis, B., Gendler, K., Goodstein, D., Gribskov, M., Grimwood, J., Groover, A., Gunter, L., Hamberger, B., Heinze, B., Helariutta, Y., Henrissat, B., Holligan, D., Holt, R., Huang, W., IslamFaridi, N., Jones, S., Jones-Rhoades, M., Jorgensen, R., Joshi, C., Kangasjärvi, J., Karlsson, J., Kelleher, C., Kirkpatrick, R., Kirst, M., Kohler, A., Kalluri, U., Larimer, F., Leebens-Mack, J., Leplé, J.C., Locascio, P., Lou, Y., Lucas, S., Martin, F., Montanini, B., Napoli, C., Nelson, D.R., Nelson, C., Nieminen, K., Nilsson, O., Pereda, V., Peter, G., Philippe, R., Pilate, G., Poliakov, A., Razumovskaya, J., Richardson, P., Rinaldi, C., Ritland, K., Rouzé, P., Ryaboy, D., Schmutz, J., Schrader, J., Segerman, B., Shin, H., Siddiqui, A., Sterky, F., Terry, A., Tsai, C.J., Uberbacher, E., Unneberg, P., Vahala, J., Wall, K., Wessler, S., Yang, G., Yin, T., Douglas, C., Marra, M., Sandberg, G., Van de
Peer, Y. \& Rokhsar, D. 2006. The genome of black cottonwood, Populus trichocarpa (Torr. \& Gray). Science 313: 1596-1604.

Tuskan, G.A., Gunter, L.E., Yang, Z.K., Yin, T.M., Sewell, M.M. \& DiFazio, S.P. 2004. Characterization of microsatellites revealed by genomic sequencing of Populus trichocarpa. Canad. J. Forest Res. 34: 85-93.

Uga, Y., Fukuta, Y., Cai, H.W., Iwata, H., Ohsawa, R., Morishima, H. \& Fujimura, T. 2003. Mapping QTLs influencing rice floral morphology using recombinant inbred lines derived from a cross between Oryza sativa L. and Oryza rufipogon Griff. Theor. Appl. Genet. 107: 218-226.

Van der Schoot, J., Pospiskova, M., Vosman, B. \& Smulders, M.J.M. 2000. Development and characterization of microsatellite markers in black poplar (Populus nigra L.). Theor. Appl. Genet. 101: 317-322.

Van Loo, M., Joseph, J.A., Heinze, B., Fay, M.F. \& Lexer, C. 2008. Clonality and spatial genetic structure in Populus ${ }^{\times}$canescens and its sympatric backcross parent $P$. alba in a Central European hybrid zone. New Phytol. 177: 506-516.

Via, S. \& West, J. 2008. The genetic mosaic suggests a new role for hitchhiking in ecological speciation. Molec. Ecol. 17: 4334-4345.

Welch, M.E. \& Rieseberg, L.H. 2002. Habitat divergence between a homoploid hybrid sunflower species, Helianthus paradoxus (Asteraceae), and its progenitors. Amer. J. Bot. 89: 472-478.

White, R., Rentice, H.C. \& Verwist, T. 1988. Automated image acquisition and morphometric description. Canad. $J$. Bot. 66: 450-459.

Whitham, T.G. 1989. Plant hybrid zones as sinks for pests. Science 244: 1490-1493.

Whitham, T.G., Bailey, J.K., Schweitzer, J.A., Shuster, S.M., Bangert, R.K., Leroy, C.J., Lonsdorf, E.V., Allan, G.J., DiFazio, S.P., Potts, B.M., Fischer, D.G., Gehring, C.A., Lindroth, R.L., Marks, J.C., Hart, S.C., Wimp, G.M. \& Wooley, S.C. 2006. A framework for community and ecosystem genetics: from genes to ecosystems. Nature Rev. Genet. 7: 510-523.

Wu, C.-I. 2001. The genic view of the process of speciation. J. Evol. Biol. 14: 851-865.

Wu, R., Bradshaw, H.D. \& Stettler, R.F. 1997. Molecular genetics of growth and development in Populus. V. Mapping quantitative trait loci affecting leaf variation. Amer. J. Bot. 84: 143-153.

Yatabe, Y., Kane, N.C., Scotti-Saintagne, C. \& Rieseberg, L.H. 2007. Rampant gene exchange across a strong reproductive barrier between the annual sunflowers, Helianthus annuus and $H$. petiolaris. Genetics 175: 1883-1893.

Yoshioka, Y., Iwata, H., Ohsawa, R. \& Ninomiya, S. 2004. Analysis of petal shape variation of Primula sieboldii by elliptic Fourier descriptors and principal component analysis. Ann. Bot. 94: 657-664.

Zelditch, M., Swiderski, D., Sheets, D.H. \& Fink, W. 2004. Geometric Morphometrics for Biologists: A Primer. Elsevier Academic Press, St. Louis. 